\title{
ANALISIS PENERIMAAN ALAT TRANSPORTASI IKAN SEGAR BERPENDINGIN MENGGUNAKAN PENDEKATAN TECHNOLOGY ACCEPTANCE MODELS
}

\section{Acceptance Analysis of Refrigerated Fish Container for Retailers Using Technology Acceptance Models Approach}

\author{
Arif Rahman Hakim ${ }^{1 *}$, Zaenal Arifin Siregar ${ }^{1}$, Tri Nugroho Widianto ${ }^{1}$ dan Agus Heri Purnomo ${ }^{2}$ \\ ${ }^{1}$ Loka Penelitian dan Pengembangan Mekanisasi Pengolahan Hasil Perikanan, JI. Imogiri Barat Km 11,5 \\ Bantul - DI Yogyakarta, Indonesia \\ ${ }^{2}$ Pusat Penelitian dan Pengembangan Daya Saing Produk dan Bioteknologi Kelautan dan Perikanan \\ Jl. K.S.Tubun Petamburan VI, Jakarta Pusat, Indonesia \\ * Korespondensi Penulis: arifrahmanh11@gmail.com \\ Diterima: 26 Februari 2016; Disetujui: 30 Mei 2016
}

\begin{abstract}
ABSTRAK
Perbaikan sistem distribusi ikan segar perlu terus ditingkatkan sehingga kualitas ikan terjamin, salah satunya ialah penggunaan alat transportasi ikan segar berpendingin (Altis-2). Penelitian terdahulu telah membuktikan bahwa Altis-2 sangat membantu pedagang ikan segar keliling dalam menjaga mutu ikan dagangannya. Penelitian ini difokuskan pada uji penerimaan Altis-2 oleh pedagang ikan segar di 6 lokasi melalui pendekatan technology acceptance models (TAM). Tujuannya adalah untuk mengetahui faktor yang paling mempengaruhi penerimaan Altis-2. Variabel yang digunakan ialah kemudahan, kegunaan dan penerimaan alat tersebut. Hasil analisa membuktikan bahwa kemudahan pengoperasian Altis-2 menjadi faktor paling berpengaruh pada penerimaan pedagang. Salah satu tahapan operasional penggunaan Altis-2 yang memerlukan perbaikan ialah proses pelepasan rangka dari motor dan ukuran lebar dari Altis-2.
\end{abstract}

KATAKUNCI: alat transportasi ikan berpendingin, technology acceptance models (TAM), pedagang ikan, analisis penerimaan

\begin{abstract}
Improvements of fresh fish distribution system is continuously upgraded so the quality of fish can be assured, one of which is the use of refrigerated fish container (Altis-2). Previous research has proven that Altis-2 was able to help fresh fish retailer in maintaining the fish quality. This study was focused on the acceptance test of Altis-2 by fresh fish retailers in 6 regions using technology acceptance models (TAM) approach. The objective is to determine the most influencing factor to the Altis-2 acceptance. The variable used were the handiness, usefulness and acceptance of this equipment. The results of the analysis proved that the handiness of Altis-2 operation became the most influencing factor in retailer acceptance. One of the operational activities required to improve the handiness of the process is simplification of framework removing from the motorcycle and adjusting the width of Altis-2.
\end{abstract}

KEYWORDS: refrigerated fish container, technology acceptance models (TAM), fish retailer, acceptance analysis

\section{PENDAHULUAN}

Sektor perikanan merupakan salah satu sektor untuk mendukung ketahanan pangan di Indonesia. Ikan merupakan sumber pangan dengan komposisi gizi yang lengkap baik protein maupun lemak tak jenuhnya, sehingga permintaan masyarakat terhadap ikan untuk konsumsi terus meningkat (Antaranews, 2016). Ikan disebut juga perishable food atau bahan pangan yang mudah rusak. Kerusakan atau penurunan mutu ikan terjadi lebih cepat bila suhu penyimpanan meningkat, karena peningkatan suhu memacu metabolisme mikroba pembusuk, reaksi oksidasi dan aktivitas enzimatik (Kotta, Moeller, OravKotta \& Paernoja, 2014; Pack et al., 2014).

Teknologi pendinginan adalah teknologi yang paling mudah digunakan untuk mempertahankan kualitas ikan termasuk penerapan sistem rantai dingin. Dengan sistem ini kondisi dingin ikan terus dijaga selama penanganan mulai dari penangkapan hingga ke tangan konsumen (Abad et al., 2009). Penerapan sistem 
rantai dingin mutlak diperlukan agar konsumen memperoleh ikan dengan kualitas prima. Oleh karena itu pedagang ikan segar keliling yang secara langsung mendistribusikan ikan ke tangan konsumen harus menerapkan sistem ini dalam kegiatan jual beli ikan.

Berbagai metode pendinginan digunakan oleh para pedagang ikan keliling. Yang paling umum digunakan ialah penggunaan es dalam wadah styrofoam, tetapi banyak kendala yang dihadapi terutama penggunaan es yang boros. Metode lain ialah penggunaan peti ikan berpendingin oleh pedagang ikan segar. Penelitian yang dilakukan oleh Widianto, Hermawan dan Utomo (2014), menyatakan bahwa penerapan peti ikan berpendingin mampu mempertahankan suhu dan mutu kesegaran ikan selama proses penjualan ikan eceran oleh pedagang ikan keliling. Peti ikan berpendingin disebut dengan Altis-2 merupakan singkatan dari alat transportasi ikan segar untuk kendaraan roda 2 .

Altis-2 terdiri dari dua buah peti berinsulasi yang dirangkaikan dengan dudukan dan diletakkan di sebelah kanan dan kiri sepeda motor. Sistem pendingin alat ini menggunakan sistem thermoelectric cooling (TEC) dengan sumber energi arus $D C$ dari aki. Prinsip kerja sistem TEC adalah pemanfaatan terjadinya perbedaan suhu antara sisi panas dan sisi dingin modul TEC atau peltier (Sulistyanto, 2014). Setelah diberi arus DC, bagian sisi dingin peltier digunakan untuk menyerap panas ruang penyimpanan yang kemudian dilepas ke lingkungan melalui sisi panas elemen peltier sehingga suhu ruang menjadi rendah. Sistem TEC memiliki keunggulan lebih ramah lingkungan dibandingkan dengan sistem pendingin konvensional menggunakan refrigerant.

Sebelumnya Altis-2 telah diuji lapang di Kabupaten Gunungkidul oleh pedagang ikan segar. Hasil uji coba peti dalam kondisi kosong menunjukkan bahwa suhu dapat mencapai $11,1-15,5^{\circ} \mathrm{C}$. Setelah diisi $30 \mathrm{~kg}$ ikan yang sebelumnya telah didinginkan hingga $0-1{ }^{\circ} \mathrm{C}$ dan dilakukan praktek penjualan ikan eceran selama 3-
3,8 jam, suhu ikan meningkat tetapi hanya sampai $3^{\circ} \mathrm{C}$ dengan nilai mutu organoleptik dan jumlah bakteri yang hampir tidak berubah. Dapat dikatakan bahwa peti ikan berpendingin mampu mempertahankan suhu dan mutu kesegaran ikan selama proses penjualan ikan eceran oleh pedagang ikan keliling (Widianto et al., 2014). Namun pengujian baru dilakukan pada satu pedagang dan satu lokasi sehingga belum diketahui penerimaannya bila diujikan di lokasi yang berbeda.

Sebelum diterapkan, teknologi baru perlu dikaji penerimaannya oleh pengguna. Model technology acceptance models (TAM) biasa digunakan untuk menilai persepsi pengguna teknologi baru. Model ini merupakan model yang menjelaskan penerimaan masyarakat terhadap suatu sistem atau teknologi tertentu serta opini mereka terhadap teknologi tersebut (Davis, 1989). Ciri khas dari Model TAM adalah sederhana namun bisa memprediksi penerimaan maupun penggunaan teknologi. Variabel eksternal dapat diganti dan disesuaikan dengan obyek dan topik penelitian (Fatmawati, 2015). Sebagian besar penggunaan model TAM ialah teknologi yang berbasis advanced technology (Toft, Schuitema, \& Thøgersen, 2014).

Teknologi baru seperti Altis-2 memerlukan data tingkat penerimaan dari pengguna, sebelum dipasarkan ke masyarakat. Penelitian ini bertujuan untuk mengetahui variabel yang mempengaruhi penerimaan Altis-2 oleh para pedagang ikan menggunakan model TAM dan perbaikan yang harus dilakukan sebelum diproduksi massal.

\section{BAHAN DAN METODE}

\section{Bahan Uji}

Teknologi yang diujikan kepada pengguna ialah Altis-2. Spesifikasi Altis-2 yang diuji merupakan adopsi dari penelitian Widianto et al. (2014) yang terdiri dari peti berinsulasi, sistem pendingin TEC, kotak

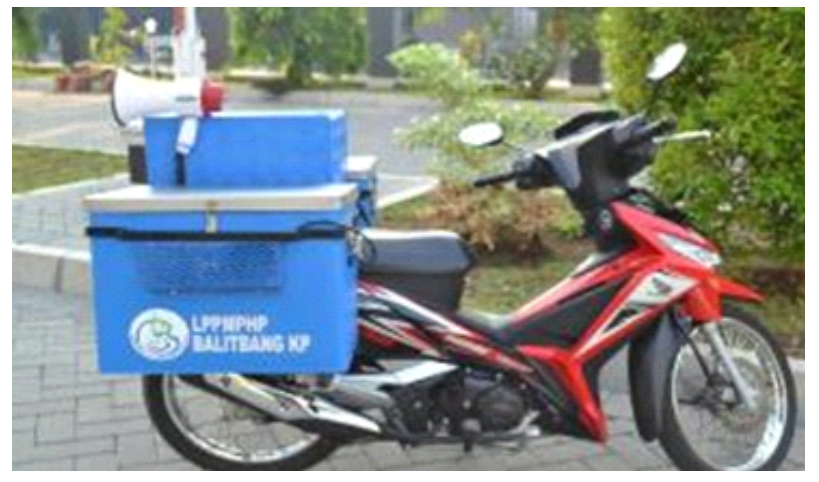

Gambar 1. Altis-2 pada motor roda 2.

Figure 1. Altis-2 installed on motor cycle. 
aksesoris dan dudukan. Gambar Altis-2 yang diuji tersaji pada Gambar 1.

\section{Partisipan dan Prosedur}

Penelitian ini dibantu oleh volunteer untuk menggunakan Altis-2. Volunteer disini ialah masyarakat yang berprofesi sebagai pedagang ikan segar keliling. Calon volunteeryang dipilih adalah yang memenuhi kriteria antara lain frekuensi penjualan ikan bersifat harian, kapasitas peti existing maksimal 60 $\mathrm{kg}$, lama waktu penjualan antara 3-4 jam dan metode penjualan secara eceran. Volunteer berasal dari 6 kabupaten/kota yaitu Kabupaten Bantul, Kabupaten Gunungkidul, Kabupaten Pacitan, Kabupaten Jembrana, Kota Bitung dan Kota Padang. Pada masing-masing lokasi tersebut diambil secara acak 7 volunteer.

Setelah diperoleh volunteer yang sesuai kriteria, pelatihan pengoperasian Altis-2 dilakukan agar volunteer paham fungsi bagian-bagian Altis-2. Kepada Volunteer diberikan 1 set Altis-2 yang siap digunakan beserta buku panduan penggunaan dan kuesioner evaluasi. Proses jual beli ikan menggunakan metode yang biasa digunakan oleh volunteer. Kuesioner yang diberikan berisi tingkat kemudahan penggunaan Altis2 pada awal operasi, saat operasi, dan setelah operasi serta berisi tentang persepsi kegunaan kepada volunteer. Kuesioner tersebut diisi setelah volunteer menggunakan Altis-2 selama 1 bulan. Jangka waktu tersebut diharapkan dapat meminimalisir faktor bias yang disebabkan oleh belum terbiasanya menggunakan Altis-2. Nilai yang dimasukkan dalam kuesioner berupa angka dengan skala 1 (sulit/tidak nyaman/tidak membantu) sampai 5 (sangat mudah/ nyaman/sangat membantu) untuk menggambarkan persepsi volunteer.

Perbedaan karakteristik lokasi ditinjau berdasarkan: (1) metode penjualan ikan, yang meliputi sumber perolehan ikan dari TPI atau pengepul besar, perlakuan sebelum dijual, penggunaan es atau bahan lain; (2) jenis ikan dominan yang dijual; dan (3) topografi jalur penjualan meliputi ketinggian lokasi, kemiringan dan kondisi jalan.

\section{Statistika Deskriptif}

Nilai yang diberikan volunteer dalam kuesioner selanjutnya dievaluasi menggunakan software statistic Minitab versi 17 dan SmartPLS 3.0 untuk uji data. Untuk mengetahui pengaruh persepsi kemudahan tahapan pengoperasian Altis-2 terhadap kegunaan secara umum dan persepsi penerimaannya yang bersifat multidimensi data diolah secara Structural Equation Modelling (SEM) menggunakan Partial Least
Square (PLS). Faktor-faktor yang memiliki sifat multi dimensi biasa dianalisis menggunakan SEM (Ghozali, 2008).

Pada metode PLS setiap pertanyaan dalam kuesioner dilakukan pengujian validitas dan reliabilitasnya. Uji validitas indikator dilihat dari nilai loading factor, sementara uji reliabilitas indikator diuji menggunakan teknik cronbach's alpha, composite reliability, dan nilai average variance extracted. Indikator variabel yang sudah dinyatakan valid dan reliabel dilanjutkan dengan evaluasi model struktural berupa pengujian terhadap pernyataan-pernyataan menggunakan analisis jalur (path analysis) dengan mengukur koefisien jalur (path coefficient) dan melihat nilai $R^{2}$ variabel. Estimasi koefisien jalur dilihat dari output estimasi koefisien jalur yang diperoleh melalui prosedur bootstrapping. Tingkat signifikansi koefisien jalur yang dihasilkan dilakukan dengan membandingkan nilai t-statistik dengan nilai t-table pada tingkat signifikansi $a=1 \%$ (Ghazali, 2008).

\section{HASIL DAN BAHASAN}

\section{Pengaruh Perbedaan Lokasi Uji}

Lokasi pengujian Altis-2 meliputi Kabupaten Gunungkidul, Kota Padang, Kabupaten Pacitan, Kabupaten Jembrana, Kabupaten Bantul dan Kota Bitung. Lokasi-lokasi tersebut merupakan lokasi yang memiliki wilayah pantai, sehingga hasil perikanan laut cukup tinggi. Karakteristik topografi dan metode penjualan ikan oleh pedagang ikan segar keliling di lokasi tersebut juga berbeda-beda. Detail karakteristik tersebut bisa dilihat pada Tabel 1.

Data pada Tabel 1 memberikan informasi bahwa setiap lokasi memiliki cara berjualan ikan keliling yang berbeda. Pedagang ikan di lokasi luar jawa (Jembrana, Bitung dan Padang) menambahkan es dan air pada tempat penyimpanan ikan (styrofoam) saat berjualan ikan sedangkan di lokasi Jawa (Bantul, Gunungkidul, Pacitan) hanya menambahkan es. Kondisi topografi Gunungkidul, Pacitan dan Bitung lebih curam dibandingkan lokasi lain sehingga proses penjualan ikan ke konsumen lebih sulit.

Namun demikian hasil analisis statistik dengan selang kepercayaan $99 \%$ dan analisis post doc Turkey, menyatakan bahwa perbedaan lokasi tidak memberikan perbedaan yang signifikan terhadap penilaian secara keseluruhan kemudahan penggunaan Altis-2. Hasil tersebut bisa dilihat pada Gambar 2. Nilai yang ditampilkan merupakan nilai rata-rata, serta batas nilai terendah dan tertinggi pada tingkat kemudahan semua pengguna di tiap-tiap lokasi. 
Tabel 1. Karakteristik lokasi uji Altis-2

Table 1. Characteritics of Altis-2 test location

\begin{tabular}{|c|c|c|c|}
\hline $\begin{array}{l}\text { Lokasi/ } \\
\text { Location }\end{array}$ & $\begin{array}{l}\text { Metode Penjualan Ikan/ } \\
\text { Fish selling method }\end{array}$ & $\begin{array}{l}\text { Jenis lkan Dominan/ } \\
\text { Common Kinds of fish }\end{array}$ & $\begin{array}{c}\text { Topografi Jalur Penjualan } \\
\text { Pedagang Ikan/Topography of Fish } \\
\text { Retailer Track }\end{array}$ \\
\hline $\begin{array}{l}\text { Kab. Bantul/ } \\
\text { Bantul } \\
\text { District }\end{array}$ & $\begin{array}{l}\text { - Ikan diperoleh dari pengepul/Fish } \\
\text { obtained from wholesallers } \\
\text { - Tanpa penyimpanan sebelumnya/No } \\
\text { previous storage } \\
\text { - Penjualan menggunakan es/Sales } \\
\text { using ice } \\
\text { - Ada proses penyiangan dan } \\
\text { penimbangan ikan saat jual beli/ } \\
\text { Dressing and weighing of the fish } \\
\text { during transaction }\end{array}$ & $\begin{array}{c} \\
\text { tongkol/skipjack, } \\
\text { gurami/gouramy, } \\
\text { udang/shrimp, } \\
\text { cumi/squid, } \\
\text { bawal/pomfret, } \\
\text { kakap/snapper, } \\
\text { kembung/chub mackerel }\end{array}$ & $\begin{array}{l}\text { - Ketinggian 25-100 m dpl (meter } \\
\text { diatas permukaan laut)/Altitude of 25- } \\
100 \text { m above sea level } \\
\text { - Datar (kemiringan kurang dari 2\%) } \\
\text { /Flat (slope less than 2\%) } \\
\text { - Kondisi jalan beraspal /Asphalt } \\
\text { pavement }\end{array}$ \\
\hline $\begin{array}{l} \\
\\
\text { Kab. Gunung } \\
\text { Kidul/ } \\
\text { Gunung } \\
\text { Kidul District }\end{array}$ & $\begin{array}{l}\text { - Ikan diperoleh dari Tempat Pelelangan } \\
\text { lkan (TPI)/Fish obtained from auction } \\
\text { place } \\
\text { - Penyimpanan } 1 \text { malam, pada suhu 0- } \\
1^{\circ} \mathrm{C} / \text { One night storage at } 0-1^{\circ} \mathrm{C} \\
\text { - Penjualan menggunakan es/Sales } \\
\text { using ice } \\
\text { - Ada proses penyiangan dan } \\
\text { penimbangan ikan saat jual beli/ } \\
\text { Dressing and weighing of the fish } \\
\text { during transaction }\end{array}$ & $\begin{array}{c}\text { bawal/pomfret, } \\
\text { layur/swordfish, } \\
\text { tongkol/skipjack, } \\
\text { kuwe/trevally, } \\
\text { udang/shrimp }\end{array}$ & $\begin{array}{l}\text { - Ketinggian } 200 \text { - } 700 \text { mdpl/ Altitude } \\
\text { of } 200 \text { - } 700 \text { meters above sea level } \\
\text { - Bergelombang (kemiringan lebih } \\
\text { dari } 15-30 \% \text { )/Bumpy (slope more } \\
\text { than } 15-30 \% \text { ) } \\
\text { - Kondisi jalan beraspal/Asphalt } \\
\text { pavement }\end{array}$ \\
\hline $\begin{array}{l}\text { Kab. Pacitan/ } \\
\text { Pacitan } \\
\text { District } \\
\end{array}$ & $\begin{array}{l}\text { - Ikan diperoleh dari Tempat Pelelangan } \\
\text { lkan (TPI) /Fish obtained from auction } \\
\text { place } \\
\text { - Penyimpanan } 1 \text { malam, pada suhu 0- } \\
1^{\circ} \mathrm{C} / \text { One night storage at } 0-1^{\circ} \mathrm{C} \\
\text { - Penjualan menggunakan es/Sales } \\
\text { using ice } \\
\text { - Ada proses penyiangan dan } \\
\text { penimbangan ikan saat jual beli/ } \\
\text { Dressing and weighing of the fish } \\
\text { during transaction }\end{array}$ & $\begin{array}{c}\text { kembung/chub mackerel, } \\
\text { tongkol/skipjack, } \\
\text { layur/sword fish, ekor } \\
\text { kuning/yellow tail, ikan } \\
\text { kue/trevally, layang/ scad }\end{array}$ & $\begin{array}{l}\text { - Ketinggian } 100 \text { - } 500 \mathrm{~m} \mathrm{dpl} / \text { Altitude } \\
\text { of } 100 \text { - } 500 \text { above sea level } \\
\text { - Berbukit (kemiringan antara } 31 \text { - } \\
50 \% \text { )/Hilly (slope between } 31 \text { - 50\%) } \\
\text { - Kondisi jalan aspal dan berbatu } \\
\text { /Asphalt pavement and rocky }\end{array}$ \\
\hline $\begin{array}{l}\text { Kab. } \\
\text { Jembrana/ } \\
\text { Jembrana } \\
\text { District }\end{array}$ & $\begin{array}{l}\text { - Ikan diperoleh dari Tempat Pelelangan } \\
\text { Ikan (TPI)/Fish obtained from auction } \\
\text { place } \\
\text { - Penyimpanan } 1 \text { malam, pada suhu 0- } \\
1^{\circ} \mathrm{C} / \text { One night storage at } 0-1^{\circ} \mathrm{C} \\
\text { - Penjualan menggunakan es/Sales } \\
\text { using ice } \\
\text { - Untuk jenis ikan tertentu (udang, cumi) } \\
\text { ditambah dengan air laut/for certain } \\
\text { fish (i.e.shrimp and squid) sea water } \\
\text { were added }\end{array}$ & $\begin{array}{c}\text { tongkol/skipjack, } \\
\text { layang/scad, } \\
\text { udang/shrimp, } \\
\text { cumi/squid, } \\
\text { kerapu/grouper }\end{array}$ & $\begin{array}{l}\text { - Ketinggian } 1 \text { - } 250 \mathrm{~m} \text { dpl/Altitude of } \\
1 \text { - } 250 \text { above sea level } \\
\text { - Datar (kemiringan kurang dari } \\
2 \% \text { /Flat (slope less than } 2 \% \text { ) } \\
\text { - Kondisi jalan beraspal/Asphalt } \\
\text { pavement }\end{array}$ \\
\hline
\end{tabular}


Tabel 1. Karakteristik lokasi uji Altis-2 (lanjutan)

Table 1. Characteritics of Altis-2 test location (continued)

\begin{tabular}{|c|c|c|c|}
\hline $\begin{array}{l}\text { Lokasi/ } \\
\text { Location }\end{array}$ & $\begin{array}{l}\text { Metode Penjualan Ikan/ } \\
\text { Fish selling method }\end{array}$ & $\begin{array}{l}\text { Jenis Ikan Dominan/ } \\
\text { Common Kinds of } \\
\text { fish }\end{array}$ & $\begin{array}{c}\text { TopografiJalur Penjualan } \\
\text { Pedagang Ikan/Topography of } \\
\text { Fish Retailer Track }\end{array}$ \\
\hline $\begin{array}{l}\text { Kota } \\
\text { Bitung/ } \\
\text { Bitung } \\
\text { City }\end{array}$ & $\begin{array}{l}\text { - Ikan diperoleh dari Tempat } \\
\text { Pelelangan lkan (TPI)/Fish obtained } \\
\text { from auction place } \\
\text { - Tanpa penyimpanan } \\
\text { sebelumnya/No previous storage } \\
\text { - Penjualan menggunakan es } \\
\text { dengan penambahan air laut/ } \\
\text { Selling of fish by using mixture of } \\
\text { ice and sea water }\end{array}$ & $\begin{array}{c}\text { layang/scad, } \\
\text { tongkol/skipjack, } \\
\text { selar/yellowstripe scad, } \\
\text { kembung/chub } \\
\text { mackerel }\end{array}$ & $\begin{array}{l}\text { - Ketinggian 1- } 250 \mathrm{~m} \mathrm{dpl} / \text { Altitude of } \\
\text { 1- } 250 \text { above sea level } \\
\text { - Bergelombang (kemiringan lebih } \\
\text { dari } 15-30 \% \text { )/bumpy (slope more } \\
\text { than } 15-30 \% \text { ) } \\
\text { - Kondisi jalan aspal dan berbatu / } \\
\text { asphalt pavement and rocky }\end{array}$ \\
\hline $\begin{array}{l}\text { Kota } \\
\text { Padang/ } \\
\text { Padang } \\
\text { City }\end{array}$ & $\begin{array}{l}\text { - Ikan diperoleh dari Tempat } \\
\text { Pelelangan lkan (TPI)/Fish obtained } \\
\text { from auction place } \\
\text { - Tanpa penyimpanan } \\
\text { sebelumnya/No previous storage }\end{array}$ & $\begin{array}{c}\text { layang/scad, } \\
\text { kembung/chub } \\
\text { mackerel, selar/yellow } \\
\text { stripe scad, } \\
\text { tembang/fingerscale } \\
\text { sardine, cumi/squid }\end{array}$ & $\begin{array}{l}\text { - Ketinggian } 25-100 \mathrm{~m} \mathrm{dpl} / \text { Altitude of } \\
25-100 \text { above sea level } \\
\text { - Landai (Kemiringan lahan 2-15\%) } \\
\text { /Sloping (slope } 2-15 \%) \\
\text { Kondisi jalan aspal dan } \\
\text { berbatu/Asphalt pavement and rocky }\end{array}$ \\
\hline
\end{tabular}

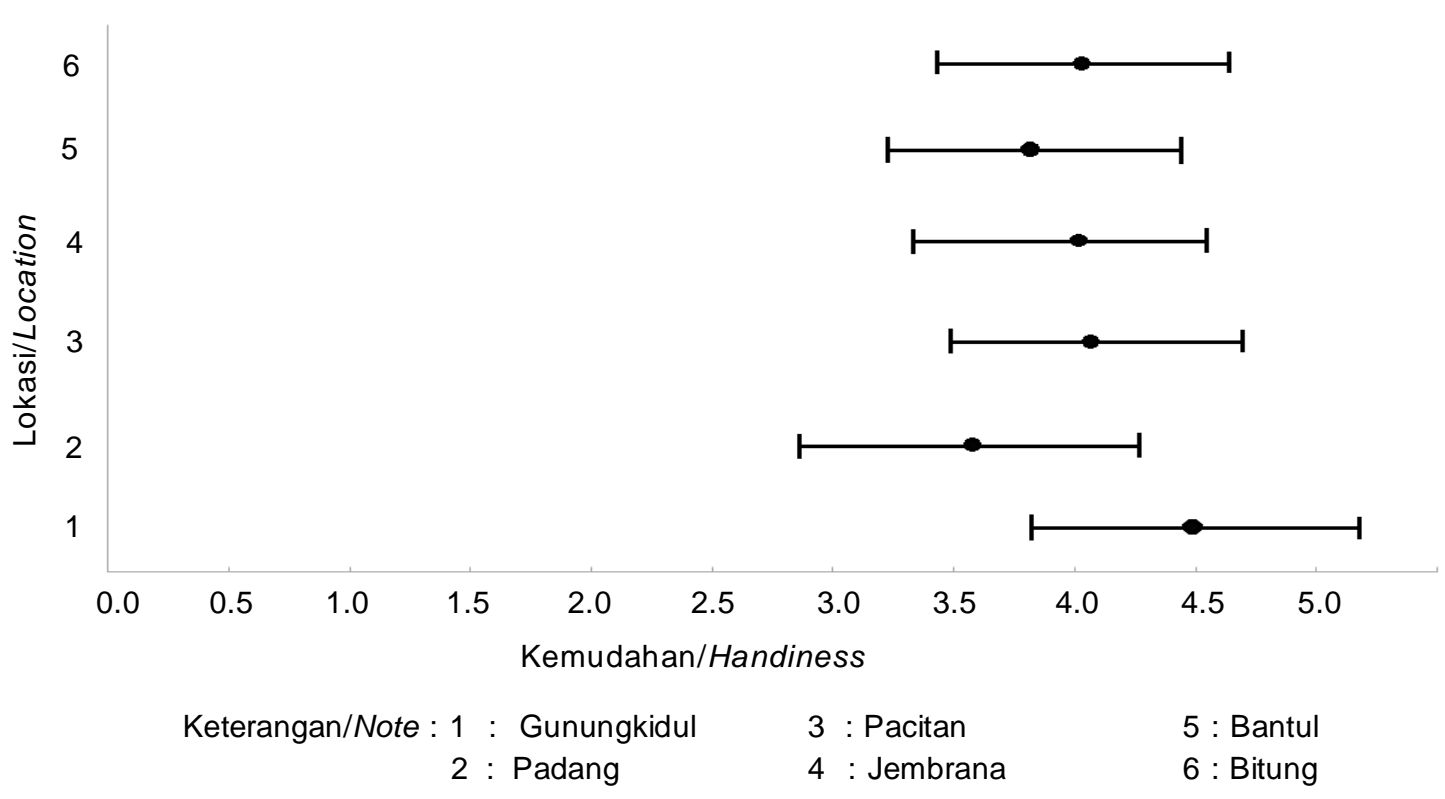

Keterangan nilai/Grade notes:

- Sangat mudah/nyaman/sangat membantu/(very handy/comfortable/usefull) : 5

- Mudah/membantu (handy/usefull) $\quad: 4$

- Sedang (moderate) $: 3$

- Agak sulit/kurang nyaman/kurang membantu (rather difficult/less comfortable/less usefull) : 2

- Sulit/tidak nyaman/tidak membantu (difficult/uncomfortable/not usefull) : 1

Gambar 2. Pengaruh perbedaan lokasi terhadap kemudahan penggunaan Altis-2.

Figure 2. Effect of different location to the handiness of Altis-2 application. 
Tabel 2. Rata-rata penilaian Altis-2 oleh pedagang Table 2. Average scoring of Altis-2 by retailer

\begin{tabular}{lcccccc}
\hline & \multicolumn{5}{c}{ Lokasi/Location } \\
\cline { 2 - 7 } & Gunung Kidul & Padang & Pacitan & Jembrana & Bantul & Bitung \\
\hline Persiapan/Preparation & $4.34^{\mathrm{a}} \pm 0.4$ & $3.74^{\mathrm{a}} \pm 0.88$ & $4.06^{\mathrm{a}} \pm 0.32$ & $3.91^{\mathrm{a}} \pm 0.25$ & $4.14^{\mathrm{a}} \pm 0.4$ & $4.26^{\mathrm{a}} \pm 0.36$ \\
Pelaksanaan/Operation & $3.79^{\mathrm{ab}} \pm 0.5$ & $3.36^{\mathrm{a}} \pm 0.66$ & $4.11^{\mathrm{a}} \pm 0.32$ & $3.79^{\mathrm{ab}} \pm 0.16$ & $3.88^{\mathrm{ab}} \pm 0.35$ & $3.71^{\mathrm{ab}} \pm 0.14$ \\
Pasca/Post Selling & $4.29^{\mathrm{a}} \pm 0.49$ & $3.00^{\mathrm{a}} \pm 1.29$ & $3.57^{\mathrm{a}} \pm 0.79$ & $3.71^{\mathrm{a}} \pm 0.49$ & $3.00^{\mathrm{a}} \pm 1.00$ & $3.43^{\mathrm{a}} \pm 0.53$ \\
\hline
\end{tabular}

Keterangan/Note : perbedaan notasi huruf menunjukkan nilai berbeda signifikan/different letter showing significant difference

Keterangan nilai/Grade notes:

- Sangat mudah/nyaman/sangat membantu/(very handy/comfortable/usefull) $\quad: 5$

- Mudah /membantu (handy/usefull) $\quad: 4$

- Sedang (moderate) $\quad: 3$

- Agak sulit/kurang nyaman/kurang membantu (rather difficult/less comfortable/less usefull) $: 2$

- Sulit/tidak nyaman/tidak membantu (difficult/uncomfortable/not usefull) : 1

Selanjutnya data penilaian penerimaan pedagang masing-masing lokasi terhadap penggunaan Altis-2 pada tahapan persiapan, pelaksanaan dan pasca pengoperasian alat disajikan pada Tabel 2 yang merupakan rata-rata hasil penilaian pedagang setelah menggunakan Altis-2. Berdasarkan uji statistik, bahwa perbedaan lokasi tidak memberikan perbedaan signifikan $(p>0,01)$ terhadap nilai dari persiapan dan pasca pemakaian Altis-2. Sedangkan pada tahap pelaksanaan/saat operasi terdapat perbedaan, pedagang di Kota Padang memberikan nilai rendah pada saat pelaksanaan jual beli menggunakan Altis2 yaitu 3,36 . Hal ini disebabkan saat operasi terdapat kendala yaitu adanya kebiasaan pemberian air pada peti yang sulit diubah. Persyaratan tidak menggunakan air melebihi tinggi posisi kipas pada Altis-2 menyebabkan pedagang memberi nilai lebih rendah. Gangale, Mengolini dan Onyeji (2013) menyatakan bahwa introduksi teknologi baru bisa dipengaruhi oleh kebiasaan/budaya yang berlaku di suatu komunitas,

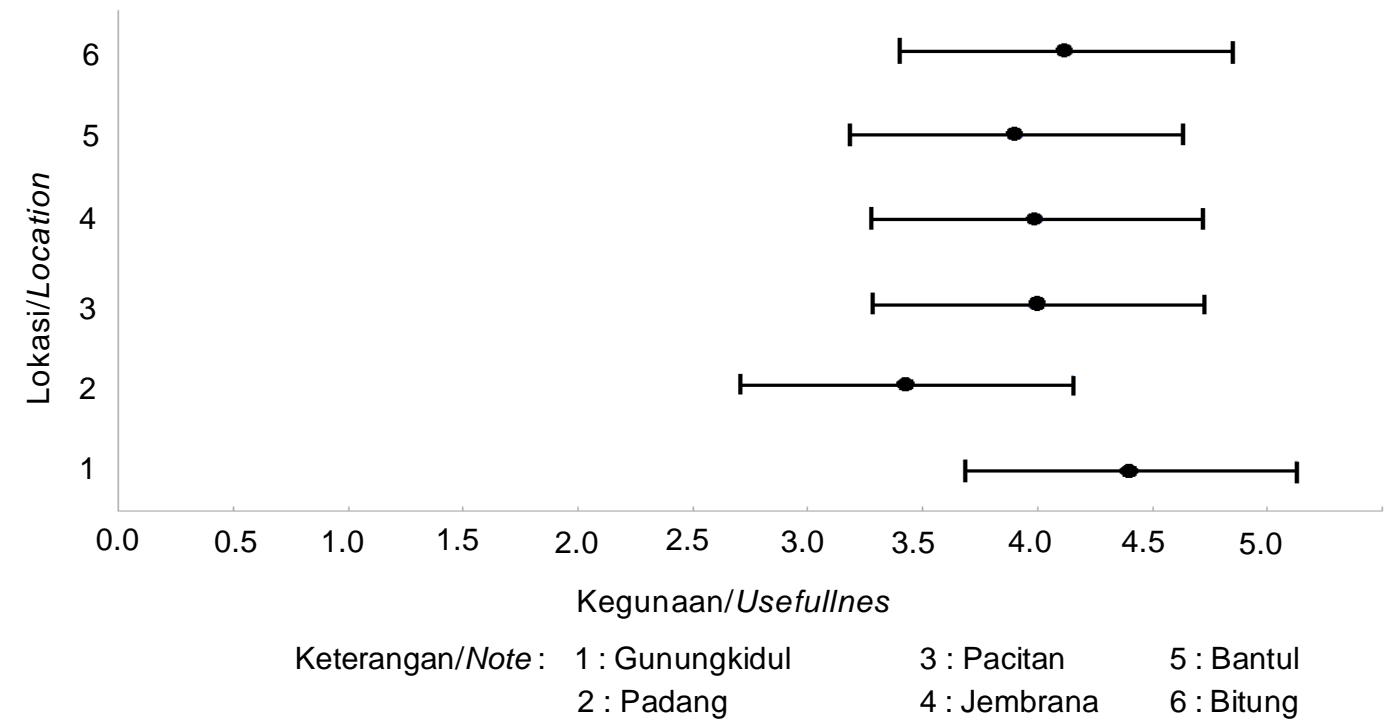

Keterangan nilai/Grade notes:

- Sangat mudah/nyaman/sangat membantu/(very handy/comfortable/usefull) $\quad: 5$

- Mudah /membantu (handy/usefull) $\quad: 4$

- Sedang (moderate) $\quad: 3$

- Agak sulit/kurang nyaman/kurang membantu (rather difficult/less comfortable/less usefull) $\quad: 2$

- Sulit/tidak nyaman/tidak membantu (difficult/uncomfortable/not usefull)

Gambar 3. Pengaruh perbedaan lokasi terhadap penggunaan Altis-2.

Figure 3. Effect of different location to the usefulness of Altis-2 application. 
karena kebiasaan akan sangat sulit dihilangkan. Dalam hal ini pedagang ikan di Kota Padang memiliki ciri yang cukup berbeda dibandingkan lokasi uji lain.

Pembatasan penggunaan air hingga melewati batas letak kipas Altis-2 bertujuan agar kipas pendingin Altis-2 mampu bekerja optimal untuk menghembuskan udara dingin ke seluruh ruang peti. Kondisi ini juga akan menjadi pertimbangan dalam produksi massal Altis-2 di kemudian hari yang memerlukan pilihan lain untuk posisi kipas pendingin pada Altis-2.

Nilai kegunaan Altis-2 selama uji berkisar antara 3,4-4,4 (Gambar 3) yang menunjukkan bahwa penerimaan alat ini antara sedang dan mudah hingga membantu para pedagang berjualan ikan segar. Pedagang ikan di Kota Padang memberi nilai lebih rendah daripada lokasi lain, hal ini kemungkinan karena tingkat kemudahan Altis-2 menurut mereka masih rendah. Namun demikian nilai tersebut tidak memberikan perbedaan yang signifikan.

Nilai penerimaan Altis-2 memberikan kecenderungan yang sama dengan nilai kegunaan. Nilai penerimaan berkisar antara 3,8-4,8, nilai terendah berada di lokasi Kota Padang dan tertinggi berada di lokasi Kabupaten Gunungkidul. Nilai penerimaan masing-masing lokasi bisa dilihat pada
Gambar 4. Penerimaan merupakan persepsi dari keseluruhan Altis-2 baik kemudahan maupun kegunaan. Altis-2 akan diterima oleh pedagang apabila mereka menilai bahwa alat tersebut berguna untuk kegiatan penjualan ikan segar. Senada dengan penelitian Wahyudi (2011) tentang analisis sikap dan niat menggunakan mini laptop, bahwa persepsi penerimaan teknologi baru akan dipengaruhi oleh kegunaan teknologi baru tesebut.

\section{Technology Acceptance Models (TAM)}

Setelah diperoleh informasi tentang peneriman Altis-2 di beberapa lokasi, tahapan selanjutnya ialah membuat model untuk mengetahui faktor apa saja yang memberikan pengaruh terhadap penerimaan Altis-2 melalui technology acceptance models (TAM).

TAM digunakan dalam penelitian untuk pengujian tingkat penerimaan pedagang terhadap teknologi Altis2. Pengujian meliputi faktor-faktor yang mempengaruhi penggunaan Altis-2 oleh pedagang ikan. Pengolahan data lebih lanjut dilakukan dengan menggunakan metode structural equation model (SEM) menggunakan partial least square (PLS). Untuk pengolahan data pada penelitian ini digunakan software Smart PLS 3.0. Menurut Nurwullan, Suharno dan Netti (2015), kelebihan analisis SEM PLS ialah

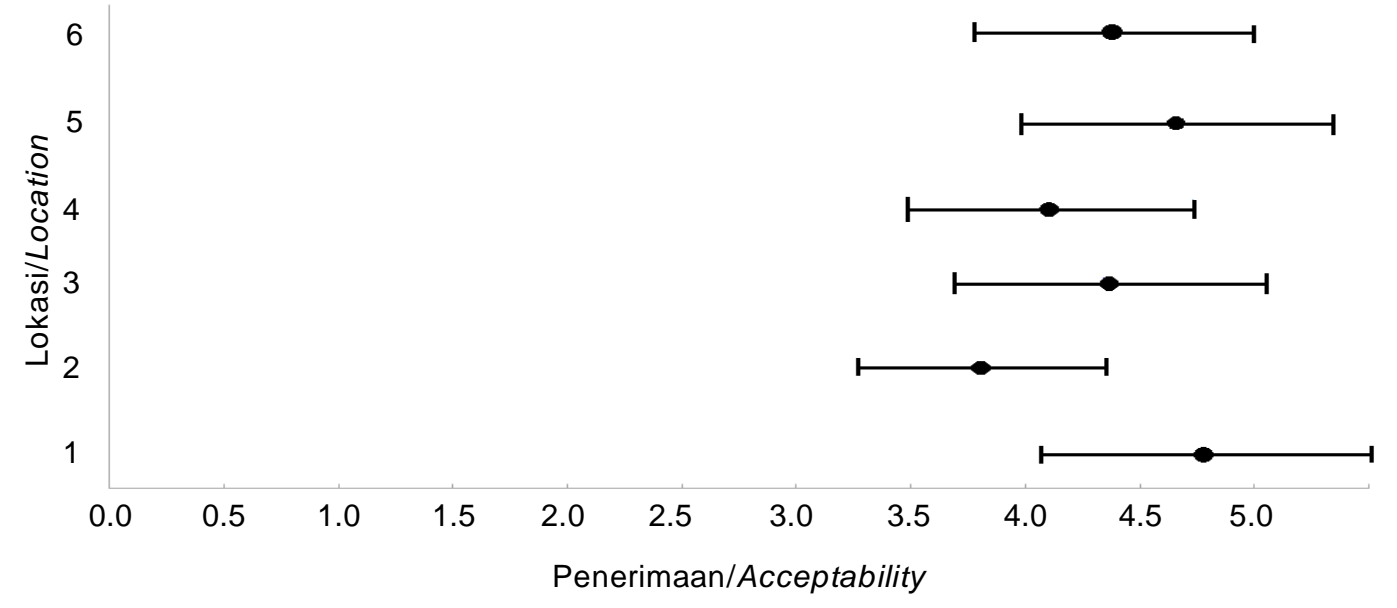

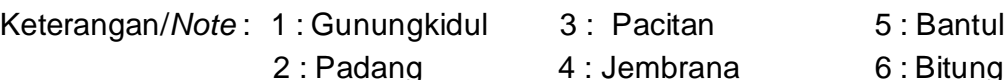

Keterangan nilai/Grade notes:

- Sangat mudah/nyaman/sangat membantu/(very handy/comfortable/usefull) $\quad: 5$

- Mudah /membantu (handy/usefull)

- Sedang (moderate)

- Agak sulit/kurang nyaman/kurang membantu (rather difficult/less comfortable/less useful) $\quad: 2$

- Sulit/tidak nyaman/tidak membantu (difficult/uncomfortable/not usefull)

Gambar 4. Pengaruh perbedaan lokasi terhadap penerimaan Altis-2.

Figure 4. Effect of different location to the acceptability of Altis-2. 
model yang digunakan merupakan model reflektif (arah hubungan kausalitas dari konstruksi laten/variabel terukur ke indikator/variabel pengukur) sehingga indikator-indikator variabel dapat diukur secara langsung. SEM PLS menggunakan pendekatan Variance Based SEM yang digolongkan sebagai jenis non-parametrik. Oleh karena itu dalam pemodelannya PLS tidak memerlukan data dengan distribusi normal (Hussein, 2015).

Model yang diperoleh selanjutnya digunakan sebagai alat ukur yang menggambarkan faktor-faktor apa saja yang mempengaruhi penerimaan Altis-2. Indikator yang disusun dalam model ini diuji validitas dan reliabilitasnya. Uji validitas dilakukan untuk mengetahui tingkat kesesuaian pengukuran dengan tujuan awal pengukuran. Uji reliabilitas bertujuan menguji seberapa jauh butir-butir pernyataan dalam kuesioner dapat dimengerti oleh responden.

Indikator uji validitas dan reliabilitas menggunakan nilai composite reliability, average variance extracted (AVE) dan Cronbach's alpha. Hasil uji ditunjukkan pada Tabel 3. Menurut Govindajaru Chandra dan Siregar (2012), bahwa suatu variabel dinyatakan reliable (handal) apabila nilai composite variable >
0,6, nilai $A V E>0,5$ dan Cronbach's alpha > 0,6. Berdasarkan hasil tersebut, variabel yang digunakan telah sesuai dan konsisten dalam memperhitungkan tingkat penerimaan.

Variabel yang disusun dalam model meliputi kemudahan, kegunaan dan penerimaan. Kemudahan berisi beberapa pernyataan terkait kemudahan penggunaan Altis-2 mulai dari 1) persiapan berjualan yang meliputi proses meletakkan Altis-2 di atas kendaraan bermotor, memasang ruang penyimpanan di atas dudukan hingga proses menyambung sistem kelistrikan motor ke ruang penyimpanan ikan, 2) saat pelaksanaan/melakukan operasi, pedagang menilai pengaruh menggunakan Altis-2 saat mengendarai sepeda motor hingga saat melayani pembeli, 3) setelah selesai operasi yaitu proses melepas alat dari atas kendaraan bermotor dan membersihkan peti.

Setelah masing-masing indikator variabel valid dan reliable (handal) maka dilanjutkan dengan evaluasi model struktural untuk pengujian hipotesis. Proses tersebut dilakukan dengan menggunakan path analysis (analisis jalur) untuk mengukur path coefficient (koefisien jalur) antara variabel dalam hipotesis dan

Tabel 3. Hasil uji reliabilitas

Table 3. Test result of reliability

\begin{tabular}{lccc}
\hline \multicolumn{1}{c}{$\begin{array}{c}\text { Variabel/ } \\
\text { Variable }\end{array}$} & $\begin{array}{c}\text { Komposit Reliabilitas/ } \\
\text { Composite Reliability }\end{array}$ & $\begin{array}{c}\text { Rerata Variasi/ } \\
\text { Average Variance } \\
\text { Extracted }\end{array}$ & $\begin{array}{c}\text { Nilai Cronbach Alpha/ } \\
\text { Cronbach's Alpha }\end{array}$ \\
\hline Kemudahan / Handiness & 0.82 & 0.60 & 0.69 \\
Kegunaan / Usefullness & 1 & 1 & 1 \\
Penerimaan / Acceptance & 1 & 1 & 1 \\
\hline
\end{tabular}

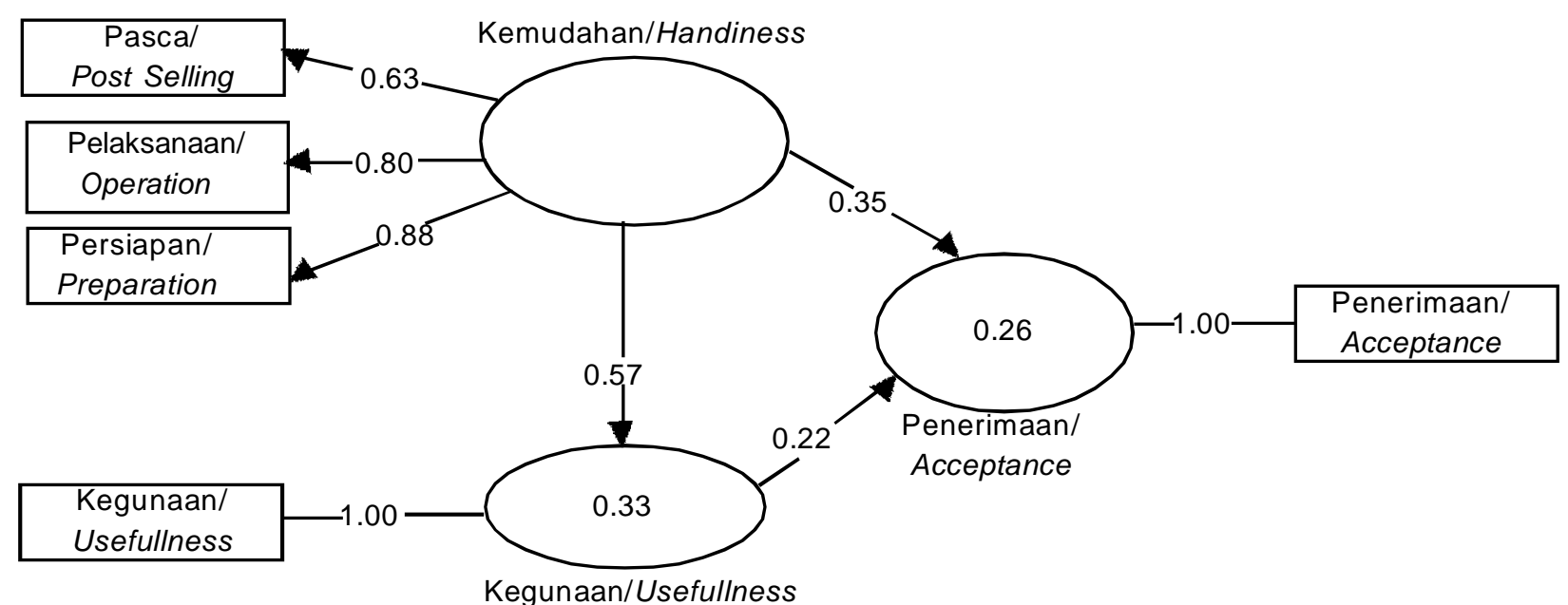

Gambar 5. Diagram jalur R kuadrat.

Figure 5. Path diagram of $R$-square. 
nilai $R^{2}$ ( $R$-square) variabel. Hubungan antara variabel laten dapat dilihat pada output grafik dari SmartPLS software yang disajikan pada Gambar 5 . Nilai $R^{2}=$ 0,26 menunjukkan bahwa pengaruh dari variabel kegunaan dan kemudahan hanya dapat menjelaskan $26,3 \%$ terhadap variabel penerimaan menggunakan model ini.

Nilai path coefficient (Tabel 4) menunjukkan bahwa hubungan antara kemudahan dengan kegunaan adalah signifikan dengan t-statistik sebesar 2,59 (> 1,65). Nilai koefisien jalur adalah positif yaitu sebesar 0,57 yang menunjukkan bahwa arah hubungan antara kemudahan dan kegunaan adalah positif. Dengan demikian dapat dikatakan bahwa kemudahan berpengaruh terhadap kegunaan Altis-2.

Demikian juga hubungan antara kemudahan dengan penerimaan adalah signifikan dengan $\mathrm{t}$-statistik sebesar 2,24 $(>1,65)$. Nilai koefisien jalur adalah positif yaitu sebesar 0,35 yang menunjukkan bahwa arah hubungan antara kemudahan dan penerimaan adalah positif. Dengan demikian dapat dikatakan bahwa kemudahan berpengaruh terhadap penerimaan Altis-2.

Sedangkan hubungan antara kegunaan dengan penerimaan dengan nilai t-statistik $(1,44)$ lebih kecil dari nilai t-tabel $(1,65)$ menunjukkan tidak adanya pengaruh signifikan terhadap penerimaan, karena nilai t-statistik kurang dari 1,65 yang merupakan daerah penolakan atau $\alpha \leq 95 \%$.

Altis-2 merupakan alat yang baru bagi pedagang ikan sehingga kemudahan operasional menjadi hal sangat penting. Para pedagang terbiasa menggunakan styrofoam, kemudian saat menggunakan Altis-2 ada banyak hal yang harus disesuaikan. Para pedagang menganggap bahwa jika
Altis-2 mudah dioperasikan pasti akan sangat berguna. Kemudahan penggunaan Altis-2 sangat mempengaruhi nilai penerimaan pedagang ikan. Hal ini juga sesuai dengan penelitian sebelumnya (Belanche,Casaló, \& Flavián, 2012 ; Henderson \& Divett, 2003; Holden \& Karsh, 2010) yang menyebutkan bahwa adopsi suatu teknologi ke konsumen sangat dipengaruhi oleh faktor kemudahan penggunaan teknologi tersebut dibandingkan faktor harga dan sikap.

Dari uraian di atas, dinyatakan bahwa kemudahan penggunaan ialah faktor utama penerimaan Altis-2, sehingga perlu dianalisa lebih lanjut mengenai variabel kemudahan tersebut. Penilaian detail tahapan kemudahan dalam penelitian ini tersaji pada Tabel 5 .

Hasil penilaian pada Tabel 5 menunjukkan bahwa nilai terendah $(3,2)$ ada pada pertanyaan kemudahan saat kegiatan selesai, yaitu proses pelepasan alat dari atas kendaraan bermotor dan saat parkir kendaraan $(3,3)$. Sebagian pedagang menyebutkan bahwa rangka dan kotak aksesoris yang berisi baterai terlalu berat sehingga tidak cukup mudah untuk mengangkatnya ketika selesai digunakan. Berdasarkan pengukuran saat produksi, berat kerangka dan kotak aksesoris yang berisi baterai memiliki berat kurang lebih $16 \mathrm{Kg}$. Hal tersebut yang menjadi kendala bagi para pedagang ikan.

Kondisi jalur berjualan yang naik turun serta jalan yang sering tidak rata membuat proses memarkir kendaraan saat melayani pembeli harus lebih hatihati. Selain hal tersebut, bahwa ukuran Altis-2 yang menurut pedagang terlalu lebar dan posisinya berada di samping sepeda motor, membuat sepeda motor terlalu miring sehingga aktivitas menimbang dan memotong ikan kurang mudah. Pedagang

Tabel 4. Koefisien jalur

Table 4. Path coefficient

\begin{tabular}{lcc}
\hline \multicolumn{1}{c}{$\begin{array}{c}\text { Hubungan Variabel/ } \\
\text { Variable relation }\end{array}$} & $\begin{array}{c}\text { Koefisien Jalur/ } \\
\text { Path Coefficient }\end{array}$ & $\begin{array}{c}\text { t-statistik/ } \\
\text { t-statistic }\end{array}$ \\
\hline $\begin{array}{l}\text { Kegunaan ---> Penerimaan } \\
\text { Usefullness ---> Acceptance }\end{array}$ & 0.22 & 1.44 \\
$\begin{array}{l}\text { Kemudahan ---> Kegunaan } \\
\text { Handiness ---> Usefullness }\end{array}$ & 0.57 & $2.59^{*}$ \\
$\begin{array}{l}\text { Kemudahan ---> Penerimaan } \\
\text { Handiness ---> Acceptance }\end{array}$ & 0.35 & $2.24^{*}$ \\
\hline
\end{tabular}

Keterangan/Note: ${ }^{*}$ t-statistic $>1.645$ 
Tabel 5. Penilaian kemudahan pengoperasian Altis-2

Table 5. Handiness scoring of Altis-2

\begin{tabular}{clc}
\hline No & \multicolumn{1}{c}{ Variabel/Variable } & Nilai/Score \\
\hline 1 & $\begin{array}{l}\text { Proses meletakkan alat transportasi (Altis-2) di atas kendaraan bermotor/Setting } \\
\text { up of Altis-2 on motorcycle }\end{array}$ & $3.5 \pm 0.2$ \\
2 & Proses merangkai Altis-2/Assembling Altis-2 & $4.0 \pm 0.2$ \\
3 & Proses membuka dan menutup peti ikan/Opening and closing fish container & $4.0 \pm 0.2$ \\
4 & Proses mengatur ikan ke peti ikan/Arranging fish in container & $4.4 \pm 0.3$ \\
5 & $\begin{array}{l}\text { Proses menyambung sistem kelistrikan motor ke peti ikan/Connecting electrical } \\
\text { system on fish container }\end{array}$ & $4.3 \pm 0.5$ \\
6 & Kemudahan mengendarai sepeda motor/Ease of riding of motorcycle & $4.4 \pm 0.3$ \\
7 & Kemudahan memarkir kendaraan bermotor/Ease of parking & $3.3 \pm 0.2$ \\
8 & Kemudahan dalam melayani pembeli, kegiatan memilih ikan/Ease in buyer serving & $3.7 \pm 0.2$ \\
& $\begin{array}{l}\text { and selecting fish } \\
9\end{array}$ & Kegiatan membuka dan menutup Altis-2 saat melayani pembeli/Opening and \\
& $\begin{array}{l}\text { closing Altis-2 while serving a buyer } \\
10\end{array}$ & Kegiatan mengambil timbangan dan pisau/Picking-up knife and scale \\
11 & Kemudahan melayani pembeli, proses pengambilan ikan/Ease in serving a buyer \\
and unloading fish & $3.7 \pm 0.4$ \\
12 & Kegiatan menimbang ikan/Fish weighing & $3.8 \pm 0.1$ \\
13 & Kegiatan memotong dan membersihkan ikan/Cutting and cleaning- up of fish \\
14 & $\begin{array}{l}\text { Kemudahan melepas alat dari atas sepeda motor saat kegiatan selesai/The ease } \\
\text { of removing the tool from the motorcycle when the activity is finished }\end{array}$ & $3.0 \pm 0.3$ \\
\hline
\end{tabular}

Keterangan nilai/Grade notes:

- Sangat mudah/nyaman/sangat membantu/(very handy/comfortable/usefull) $: 5$

- Mudah /membantu (handy/usefull) $\quad: 4$

- Sedang (moderate) $: 3$

- Agak sulit/kurang nyaman/kurang membantu (rather difficult/less comfortable/less usefull) $\quad: 2$

- Sulit/tidak nyaman/tidak membantu (Difficult/uncomfortable/not usefull)

mengatasinya dengan mengganjal penyangga sepeda motor menggunakan batu atau benda lain supaya sepeda motor lebih tegak. Hal tersebut menyebabkan penilaian terhadap kemudahan saat parkir kendaraan menjadi rendah. Pedagang menyarankan agar standar / penyangga Altis-2 diperkuat sehingga posisi sepeda motor bisa tegak saat diparkir.

Dua hal tersebut merupakan faktor yang memberikan nilai rendah terhadap kemudahan dan akan berpengaruh pada tingkat penerimaan Altis-2 oleh masyarakat atau pedagang ikan. Oleh karena itu perlu ada perbaikan dalam hal penyederhanaan proses pelepasan rangka dari motor serta mengubah ukuran lebar dari Altis-2 menjadi lebih ramping.

\section{KESIMPULAN}

Pengukuran tingkat penerimaan Altis-2 oleh pedagang ikan keliling menggunakan TAM memberikan gambaran bahwa variabel kemudahan pengoperasian (persiapan, pelaksanaan dan pasca pemakaian) Altis-2 sangat mempengaruhi tingkat penerimaan. Kondisi spesifik lokasi uji yang berbeda tidak menyebabkan perbedaan persepsi kemudahan, kegunaan dan penerimaan penggunaan Altis-2. Pada tahapan operasional perlu adanya beberapa perbaikan yaitu kemudahan memasang dan melepas rangka dari sepeda motor, penyesuaian ukuran lebar Altis-2, dan perubahan posisi sistem pendingin TEC hingga menjadi lebih tinggi. 


\section{DAFTAR PUSTAKA}

Abad, E., Palacio, F., Nuin, M., Zárate, A.G., Juarros, A., Gómez, J.M., \& Marco. (2009). RFID smart tag for traceability and cold chain monitoring of foods: Demonstration in an intercontinental fresh fish logistic chain. Journal of Food Engineering, 93, 394-399.

Antaranews. (2016). Kenaikan harga daging dorong peningkatan permintaan ikan. Diambil dari http:// jogja.antaranews.com/berita/337284/

Belanche, D., Casaló, L.V., \& Flavián, C. (2012). Integrating trust and personal values into the technology acceptance model: the case of e-government services adoption. Cuadernos de Economía y Dirección de la Empresa, 15,192-204.

Davis, F.D. (1989). Perceived usefulness, perceived ease of use, user acceptance of information technology. MIS Q., 13,319-340.

Fatmawati, E. (2015). Technology acceptance model (TAM) untuk menganalisis penerimaan terhadap sistem informasi perpustakaan. Jurnal lqra',09(01), 1-13.

Gangale, F., Mengolini, A., \& Onyeji, I. (2013). Consumer engagement: an insight from Smart Grid projects in Europe. Energy Policy, 60, 621-628.

Ghozali, I. (2008). Structural equation modeling metode alternatif dengan partial least square pls. edisi 2, Semarang: Badan Penerbit Universitas Diponegoro.

Govindaraju, R., Chandra, D.R., \& Siregar, Z.A. (2012). Stakeholder role in e-commerce adoption by small and medium enterprises. Proceeding of the 2012 IEEE ICMIT, 430-435.

Henderson, R., \& Divett, M.J. (2003). Perceived usefulness, ease of use and electronic supermarket use. Int. J. Hum. Comput. Stud., 59, 383-395.

Holden, R.J, \&Karsh, B.T. (2010). The technology acceptance model: its past and its future in health care. J. Biomed. Inform., 43,159-172.
Hussein, A.S. (2015). Penelitian bisnis dan manajemen menggunakan partial least squares (PLS) dengan smartPLS 3.0. ModulAjar. Jurusan Manajemen Fakultas Ekonomi dan Bisnis Universitas Brawijaya. Malang.

Kotta, J., Moeller, T., Orav-Kotta, H., \& Paernoja, M. (2014). Realized niche width of a brackish water submerged aquatic vegetation under current environmental conditions and projected influences of climate change. Marine Environmental Research, 102, 88-101.

Nurwullan, E., Suharno, Netti, T. (2015). Aplikasi partial least square dalam pengujian implikasi jaringan kerjasama dan inovasi usaha mikro kecil pengolahan kedelai. Informatika Pertanian, 24 (2), 205-214.

Pack, E.C., Lee, S.H., Kim, C.H., Lim, C.H., Sung, D.G., Kim, M.H., Kim, S.W. (2014). Effects of environmental temperature change on mercury absorption in aquatic organisms with respect to climate warming. Journal of Toxicology and Environmental Health-Part A-Current Issues, 77(22-24), 1477-1490.

Sulistiyanto, N.(2014). Pemodelan Sistem Pendingin Termoelektrik pada Modul Superluminance LED. Jurnal EECCI, 8 (1), 67 -72

Toft, B., M., Schuitema, G., \& Thøgersen J., (2014). Responsible technology acceptance: model development and application to consumer acceptance of smart grid technology. Applied Energy, 134(1), 392-400.

Wahyudi, H.D. (2011). Analisis sikap dan niat menggunakan mini laptop: studi pengembangan model penerimaan teknologi. Jurnal Ekonomi Bisnis, 16 (1), 1-9.

Widianto, T.N., Hermawan, W., \& Utomo, B.S.B. (2014). Uji coba peti ikan segar berpendingin untuk pedagang ikan keliling. Jurnal Pascapanen dan Bioteknologi Kelautan dan Perikanan, 9(2), 185-191 
JPB Kelautan dan Perikanan Vol. 11 No. 1 Tahun 2016: 13-24 